\title{
Cryptococcal meningitis unmasking idiopathic CD4 lymphocytopenia
}

Sir,

A 50-year-old gentleman presented with fever of 8 months' and abnormal movements of the right upper 
limb of 2 weeks' duration. Eight months back, he started having low-to-moderate grade intermittent fever without any localizing symptoms. Two weeks earlier, he developed mild holocranial headache associated with 'paroxysmal tremor'-like movements, present both at rest and activity but disappearing during sleep; and inability to hold objects in the right hand. There was no history of alcoholism, vomiting, altered sensorium, visual blurring, dysphagia or herpes zoster infection. He was married and was in a monogamous relationship. There was no history of blood transfusion, surgery, needle-stick injury, intravenous drug abuse or tuberculosis. He had lost $8 \mathrm{~kg}$ of weight over the past 8 months. Fever was unresponsive to various broad-spectrum antibiotics and antitubercular therapy. Examination showed temperature of $102^{\circ} \mathrm{F}$; pulse, $100 / \mathrm{min}$; blood pressure, 130/80 mmHg; and respiratory rate, 18/min. There were abnormal involuntary movements, probably seizures which resembled coarse tremors. Rest of the general and systemic examination was normal. Laboratory investigations showed a hemoglobin level of $15.6 \mathrm{~g} / \mathrm{dl}$; total leukocyte count, 6,600/ $\mu$ l; with neutrophils, 75\%; lymphocytes, 20\%; eosinophils, $2 \%$; and monocytes, $3 \%$; platelets, 200,000/ $\mu \mathrm{l}$; and normal renal and liver function tests. Urinalysis showed plenty of pus cells; however, cultures for both bacteria and mycobacterium tuberculosis were negative. Multiple blood cultures and radiographs of the chest were normal. Bone marrow examination was normal; and cultures were negative for tuberculosis, fungus and pyogenic organisms. Ultrasonogram of the abdomen and 2D echocardiogram were normal. Magnetic resonance imaging (MRI) of the brain showed a large lesion in the left fronto-parietal and right occipital region, which was hyperintense in T2-weighted images [Figure 1]. Electroencephalogram (EEG) was normal. The cerebrospinal fluid (CSF) examination showed mildly elevated protein (80 $\mathrm{mg} / \mathrm{dl}$ ), lymphocytic pleocytosis and positive India ink test for Cryptococcus and cryptococcal antigen by latex agglutination. The CSF was negative for IgM anti-toxoplasma antibody. Serology for IgG anti-CMV antibody and HIV-1 and -2 was negative; however, CD4 cell count was $17 / \mu \mathrm{l}$.

With a diagnosis of cryptococcal meningitis with simple partial seizure, he received amphotericin B $(0.5 \mathrm{mg} / \mathrm{kg} /$ day $)$ and Flucytosine $(100 \mathrm{mg} / \mathrm{kg} /$ day $)$ for 4 weeks and carbamazepine ( $15 \mathrm{mg} / \mathrm{kg} /$ day). The seizures subsided in 3 days and fever disappeared in 7 days. At the end of 4 weeks of treatment, the CSF was still positive for cryptococcal antigen, and tablet fluconazole (400 mg/day) and trimethoprim/ sulfamethoxazole prophylaxis were started. A repeat MRI showed more than $70 \%$ resolution of the lesions [Figure 2].

Eight months later, he had simple partial seizures that responded to addition of clobazam (10 mg, twice daily).

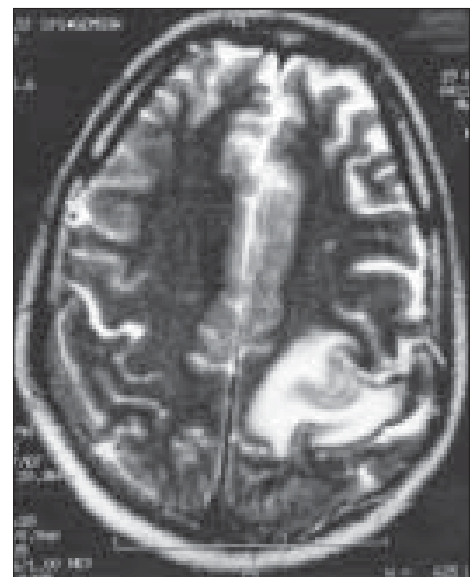

Figure 1: Axial imaging of brain demonstrating the T2-weighted hyperintense lesion on the left fronto-parietal and right occipital region

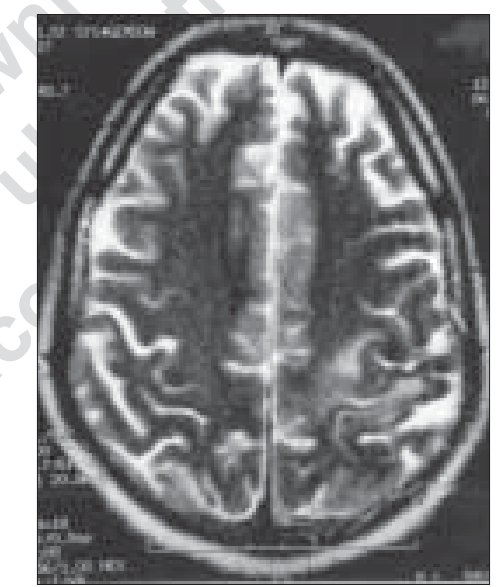

Figure 2: Axial imaging of cranial MRI T2-weighted image demonstrating the regression of lesion, 4 weeks after therapy

This time, CSF examination was normal. The seizures were attributed to parenchymal scarring. Repeat CD4 cell count was 151/ $\mu$ l. Repeat serology for HIV-1 and -2 was negative. The patient is doing well for the past 24 months.

This patient was suffering from cryptococcal meningitis, and the underlying immune-deficient state was idiopathic CD4 lymphocytopenia (ICL). Idiopathic CD4 lymphocytopenia was defined in 1992 by the US Center for Disease Control as low CD4 cell count $(<300 / \mu \mathrm{l})$ or a percentage of CD 4 cells $<20 \%$ of total T cells on at least two occasions (6 weeks apart) without any immunodeficiency or therapy associated with $\mathrm{T}$ cell depletion. ${ }^{[1]}$ This syndrome was termed severe unexplained HIV seronegative immune suppression (SUHSIS) by the World Health Organization. ${ }^{[2]}$ Its incidence varies from $0.3-1.5 \%$ in voluntary blood donors. ${ }^{[3,4]}$ The demographic and clinical features of these patients differ from those of HIV infection, and CD4+ T cell count remains stable over a period of time. ${ }^{[5]}$ Though the exact cause of CD4 lymphocytopenia is not known, it has been suggested that decreased $\mathrm{T}$ cell 
precursors in bone marrow, ${ }^{[6]}$ accelerated apoptosis of $\mathrm{CD} 4+\mathrm{T}$ cells ${ }^{[7]}$ and defective p56lac activity in T cells ${ }^{[8]}$ may play a role.

The interesting aspect of our patient was that he had presented with prolonged pyrexia, an uncommon presentation of cryptococcal meningitis, and was diagnosed as ICL incidentally. His seizures resembled coarse tremors. In the absence of clear guidelines regarding management of opportunistic infections in patients with ICL, we managed our patient with prophylaxis as described for HIV-infected patients.

Our case merits consideration as it highlights the need of increased awareness and consideration of ICL in the setting of cryptococcal meningitis.

\section{Sanjeev Jha, Parasar Ghosh*, Vikas Agarwal* Departments of Neurology and *Immunology, Sanjay Gandhi Postgraduate Institute of Medical Sciences, Lucknow, India. E-mail: sjha@sgpgi.ac.in}

\section{References}

1. Centers for Disease Control (CDC). Update: CD4+ T-lymphocytopenia in persons without evident HIV infection--United States. MMWR Morb
Mortal Wkly Rep 1992;41:578-9.

2. Global programme on AIDS: Unexplained severe immunosuppression without evidence of HIV infection. Wkly Epidemiol Rec 1992;67:30911.

3. Vermund SH, Hoover DR, Chen K. CD4+ counts in seronegative homosexual men: The Multicenter AIDS Cohort Study. N Engl J Med 1993;328:442.

4. Aledort LM, Operskalski EA, Dietrich SL, Koerper MA, Gjerset GF, Lusher JM, et al. Low CD4+ counts in a study of transfusion safety. N Engl J Med 1993;328:441-2.

5. Smith DK, Neal JJ, Holmberg SD. Unexplained opportunistic infections and CD4+ T-lymphocytopenia without HIV infection. An investigation of cases in the United States. The Centers for Disease Control Idiopathic CD4+ T-lymphocytopenia Task Force. N Engl J Med 1993;328:3739.

6. Isgro A, Sirianni MC, Gramiccioni C, Mezzaroma I, Fantauzzi A, Aiuti F. Idiopathic CD4+ lymphocytopenia may be due to decreased bone marrow clonogenic capability. Int Arch Allergy Immunol 2005;136:37984 .

7. Roger PM, Bernard-Pomier G, Counillon E, Breittmayer JP, Bernard A, Dellamonica P. Overexpression of Fas/CD95 and Fas-induced apoptosis in a patient with idiopathic CD4+ T lymphocytopenia. Clin Infect Dis $1999 ; 28: 1012-6$.

8. Hubert P, Bergeron F, Ferreira V, Seligmann M, Oksenhendler E, Debre $\mathrm{P}$, et al. Defective p56Lck activity in T cells from an adult patient with idiopathic CD4+ lymphocytopenia. Int Immunol 2000;12:449-57.

\section{Accepted on 12-09-2007}

